\title{
A simple indicator for diagnosing nitrate leaching risk below the root zone using the Tensionic tensiometers
}

\author{
Henriette Cuny ${ }^{\mathrm{a}}$, Jacques Wery ${ }^{\mathrm{a}^{*}}$, Freddy Gaufres ${ }^{\mathrm{b}}$ \\ ${ }^{\text {a } U F R ~ d ' a g r o n o m i e ~ e t ~ b i o c l i m a t o l o g i e, ~ I n r a-E n s a m, ~ 2, ~ p l a c e ~ V i a l a, ~} 34060$ Montpellier cedex 2, France \\ b Perrier-Vittel France 30310 Vergèze, France
}

(Received 6 February 1998; accepted 8 September 1998)

\begin{abstract}
Soil water potential and nitrate content in soil solution were measured simultaneously, using Tensionic tensiometers, in farmers' fields at three different sites for assessing nitrate leaching. The above measurements were made every 10 days at two depths below the rooting zone, for three different cropping systems; namely, grassland, field crops, vineyard in 1994 and 1995, and under field-grown and greenhouse-grown salads during the winter 1996-1997. A nitrate leaching risk indicator was calculated by using the soil water potential gradient and the nitrate concentration of the soil solution below the rooting zone. This approach can be used to analyse nitrate leaching under different management practices for a range of cropping systems. It was also possible to diagnose the contribution of groundwater containing a relatively high level of nitrate to nitrogen and water supply to crops. (@ Inra/Elsevier, Paris.)
\end{abstract}

nitrate / leaching / soil water potential / diagnosis / cropping systems / Tensionic tensiometer

Résumé - Un indicateur simple de diagnostic du risque de lessivage du nitrate sous la zone racinaire utilisant les tensiomètres Tensionic. Le potentiel hydrique et la teneur en nitrate de la solution du sol ont été mesurés en parcelles agricoles, à l'aide de tensiomètres Tensionic, pour calculer un indicateur de risque de lessivage du nitrate. Trois sites comprenant deux tensiomètres Tensionic situés sous la zone racinaire ont été suivis tous les 10 jours sous trois systèmes de culture (prairie, grandes cultures, vigne enherbée) en 1994 et 1995, et au cours de l'hiver 1996-97 sous des cultures de salade de plein champ et sous abri. L'indicateur de risque est défini par la teneur en nitrate de la solution du sol pendant les périodes de drainage, identifiées à l'aide du gradient de potentiel hydrique. Cette approche permet de porter un diagnostic sur des parcelles agricoles différant par l'espèce, le type de sol et l'itinéraire technique. Elle met également en évidence des situations où la nappe contribue à l'alimentation hydrique et azotée de la culture. (C Inra/Elsevier, Paris.)

lessivage / nitrate / potentiel hydrique du sol / diagnostic / système de culture

Communicated by Emmanuel Frossard (Lindau, Switzerland)

* Correspondence and reprints

Tel: +33.04.99.61.25.52; fax: +33.04.67.52.21.16; e-mail: wery @ensam.inra.fr 


\section{INTRODUCTION}

Nitrate leaching under the crop rooting zone is a major source of water table pollution [5] and an economic loss for farmers. In order to reduce nitrate losses it is necessary to identify cultivated fields with a high level of nitrate leaching risk, but also to help farmers to develop cropping systems with low economic and environmental risks. This requires diagnosis tools for nitrate leaching risk that can be used in farmers' fields at a reasonable cost. The amount of nitrate lost below the rooting zone of a crop is difficult to estimate in each field, because it depends on soil type $[18,24]$, climate $[6,24]$, genotype $[12,21]$ and cultural practices [15].

Integration of these factors can be achieved with a computer model simulating water and nitrogen dynamics in the soil-plant system [2, 13, 20]. Nevertheless, mechanistic models such as LEACHMN [17], SOILN [7] and NLEAP [30] require a large number of input variables and parameters, which are not always easy to measure in farmers' fields. Consequently these models are difficult to use for nitrate leaching risk analysis on a large number of fields with various crop species. Simplified models have been used in farmers' fields $[1,10,11]$, but as they represent soil as a series of reservoirs, these models cannot be used when capillary rise is occurring from a water table into the crop rooting zone. This situation is indeed frequent in alluvial plains which are also places of intensive cropping systems with high levels of nitrate leaching risk.

Nitrogen balances at annual timesteps have been used to calculate potentially leachable nitrogen [3, $4,23]$ of a field. This allows the diagnosis of structural excess of nitrogen in a farm [3] or in a water catchment basin [14] when there are major terms in the balance (generally mineral or organic nitrogen fertilization, $\mathrm{N}$ exports). This method cannot be used in low input farming systems where all the components of the balance are minor but none can be neglected [23]. In addition, this balance approach assumes that $\mathrm{N}$ leaching is negligible during the crop growth period, which is not necessarily true for irrigated crops [13].
Diagnosis of nitrate leaching risk in a large number of crops and in conditions where the operational models are not valid can be made with measurements of the relevant variables instead of simulating them. The nitrate flow below the crop rooting zone can be calculated from the measurement of water flow $\left(\mathrm{QH}_{2} \mathrm{O}\right)$ and its nitrate concentration $\left(\mathrm{CNO}_{3}{ }^{-}\right)$. These variables can be measured in lysimeters [19, 22 ], but this equipment is too costly for a network of fields. Soil sampling [31], or extraction of soil solution with ceramic cups $[5,28]$, have been used in farmers' fields. As these methods give access only to $\mathrm{CNO}_{3}^{-}$, they must be associated with measurements of soil water content and a water balance model to calculate $\mathrm{QH}_{2} \mathrm{O}$ The Tensionic tensiometer is a tensiometer modified to measure $\mathrm{CNO}_{3}{ }^{-}$and soil water potential simultaneously, at a cost equivalent to that of a ceramic cup [26]. Nitrate concentrations of the soil solution obtained with this type of tensiometer are generally lower than those obtained from ceramic cups after depression, probably because the Tensionic tensiometer gives an integration of the soil solution composition over a longer period of time [28]. Nevertheless the two methods gave similar evolutions of $\mathrm{CNO}_{3}{ }^{-}$during a crop cycle $[27,28]$.

The objectives of this work were i) to test if the Tensionic tensiometer can be used to measure soil water potential $(\Psi)$ and nitrate concentration of the soil solution $\left(\mathrm{CNO}_{3}^{-}\right)$in farmers' fields with a large range of cropping systems; ii) to calculate from these two variables a nitrate leaching risk indicator that can be used to compare cropping systems. This study was realised in conditions where the simulation models mentioned above were difficult to use: water table close to the rooting zone, cropping systems with low level of mineral $\mathrm{N}$ fertilization, large range of crops with few references on water and nitrogen balance (rainfed Mediterranean field crops, vineyards, field and greenhouse vegetables grown in organic farming).

\section{THEORY: DEFINITION OF A NITRATE LEACHING RISK INDICATOR}

The amount of nitrate $\left(\mathrm{QNO}_{3}{ }^{-}\right)$lost between two depths $\left(z_{1}\right.$ and $\left.z_{2}\right)$ located below the rooting zone 
depends on the amount of water drained $\left(\mathrm{QH}_{2} \mathrm{O}\right)$ and on the nitrate concentration of this water $\left(\mathrm{CNO}_{3}{ }^{-}\right)$. If $\mathrm{CNO}_{3}{ }^{-}$is constant during a period $\mathrm{dt}$, the amount of nitrate leached during this period is:

$$
\mathrm{QNO}_{3}{ }^{-}=\mathrm{QH}_{2} \mathrm{O} \times \mathrm{CNO}_{3}
$$

The periods of drainage or capillary rise below the rooting zone can be identified with measurements of soil water potential $(\Psi)$ at depths $z_{1}$ and $z_{2}$. Water flow between $z_{1}$ and $z_{2}$ depends on the mean hydraulic gradient between these two depths:

$$
\frac{\Delta \psi}{\Delta z}=\frac{\left(\psi_{z .1}-\psi_{2.2}\right)}{\left(z_{1}-z_{2}\right)}
$$

With a reference level at the soil surface and an $\mathrm{Oz}$ axis oriented to the top, positive values of the gradient indicate a drainage period and negative values indicate a capillary rise period. The risk of nitrate leaching can be defined as the conjunction of a drainage period and a nitrate concentration in the soil solution above a critical level. In the absence of information on the unsaturated zone between $z_{2}$ and the water table, this critical level can be taken as the maximal level for drinking water $\left(50 \mathrm{mg} \mathrm{NO}_{3}{ }^{-} \mathrm{L}^{-1}\right)$. According to Moutonnet et al. [26] the water in the Tensionic tensiometer ceramic cup requires a maximum of 10 days to be in equilibrium with the soil solution. This period is sufficiently short to consider that $\mathrm{CNO}_{3}^{-}$measured on day $\mathrm{j}$ can be used until the next measurement (generally 10 days later). For a period between two samplings $(j, j+10)$ we define an indicator of nitrate leaching risk below the rooting zone (i.e. between depths $z_{1}$ and $z_{2}$ ):

$$
\mathrm{RNO}_{3}{ }_{\mathrm{j}}^{-}=\mathrm{D}_{\mathrm{j}} \times \mathrm{CNO}_{3}{ }_{\mathrm{j}}^{-}
$$

$\mathrm{CNO}_{3}^{-}$is the nitrate concentration of the soil solution, averaged over the two depths of measurement $\left(z_{1}\right.$ and $\left.z_{2}\right)$, because we consider the water moving between these two depths.

$D_{j}$ is a boolean variable calculated from the hydraulic gradient between $z_{1}$ and $z_{2}$ [equation (2)]. It takes the value of 1 when there is drainage between $z_{1}$ and $z_{2}$ (positive gradient) and the value of 0 in the case of capillary rise (negative gradient). When the gradient is stable during a long period $D_{j}$ can be measured at the frequency ( 10 days) imposed by the measurement of $\mathrm{CNO}_{3}^{-}$. Nevertheless, in irrigated crops this gradient can be reversed between two irrigations and soil water potential must be measured more frequently to calculate $D_{j}$.

When the hydraulic gradient is positive, the water is moving from $z_{1}$ to $z_{2}$, and probably downward. $\mathrm{D}_{\mathrm{j}}$ takes the value 1 and $\mathrm{RNO}_{3}{ }_{\mathrm{j}}=\mathrm{CNO}_{3}{ }_{\mathrm{j}}$.

When the gradient is negative the water is rising from $z_{2}$ to $z_{1}$ and there is no risk of nitrate leaching. $\mathrm{D}_{\mathrm{j}}=0$ and $\mathrm{RNO}_{3}{ }_{\mathrm{j}}=0$. If soil dehydration continues below the lower limit of Tensionic tensiometer functioning $(\Psi<-80 \mathrm{kPa}$ ), we can assume that the water flow between $z_{2}$ and $z_{1}$ remains oriented upward, at least until the resumption of rainfall or irrigation. During this period we assume $\mathrm{D}_{\mathrm{j}}=0$ and $\mathrm{RNO}_{3}{ }_{\mathrm{j}}^{-}$remains at 0 .

When the gradient is null it indicates that there is a water table or a zero flow plan between $z_{1}$ and $z_{2}$. The latter situation can only be the result of a local reduction of soil water potential between $z_{1}$ and $z_{2}$, as we assume that there are no roots to extract water at $z_{2}$. Water flow is oriented downward between $z_{1}$ and the zero flow plan, but it is oriented upward between $z_{2}$ and this plan. There is no risk of drainage at depth $z_{2}$ and we can assume that $D_{j}=0$ and then $\mathrm{RNO}_{3 \mathrm{j}}{ }^{-}=0$. If there is a water table between $z_{1}$ and $z_{2}$, matric potential measured at $z_{2}$ will be null or positive. It is impossible to allocate a value to $D_{j}$ and to calculate the nitrate leaching risk indicator. Nevertheless it indicates a risk of pollution of the water table by the cropping system, because of its proximity to the soil surface. In addition, capillary rise from the water table can bring significant amounts of water and nitrogen into the crop rooting zone. The information given by the Tensionic tensiometer on the presence of a water table and on its nitrate concentration is an important result of the diagnosis.

\section{MATERIALS AND METHODS}

\subsection{The Tensionic tensiometer}

The Tensionic tensiometer (SDEC France, 37310 Reignac sur Indre, France) is made of a 'high flow' ceramic cup sealed at the tip of a PVC tube and linked to 
three capillary nylon tubes [26]. Two of the capillaries reach the bottom of the ceramic cup, one for the measurement of water potential and the other for extracting the soil solution. The third capillary is for air bleeding. The hydraulic conductivity of the ceramic is $2.5 \cdot 10^{-5}$ $\mathrm{m} . \mathrm{s}^{-1}$, which allows an equilibrium between the Tensionic tensiometer solution and the soil solution in 10 days $[26,27]$. A pressure probe allows the measurement of soil water potential $(\Psi)$, according to the method of Thony et al. [32]. As this measurement does not disturb the equilibrium between the soil solution and the ceramic cup solution, it can be repeated as often as necessary.

The Tensionic tensiometer solution was extracted with a syringe every 10 days, after the measurement of $\Psi$. In order to obtain $\mathrm{CNO}_{3}^{-}$, the nitrate concentration of the extracted solution was multiplied by a coefficient to take into account the dilution by the water contained in the capillary tubes [26]: $(4 \times z+12) / 12$, where $z$ (in $\mathrm{m}$ ) was the depth of the ceramic cup in the soil. When $\Psi$ was lower than $-45 \mathrm{kPa}$, the extracted volume was frequently lower than the ceramic cup and capillary volume (not shown). In this case, the volume of solution extracted was measured and used in the calculation of the dilution coefficient.

Before insertion into the soil the ceramic cup was immerged into distilled water and submitted to several depressions, in order to saturate the ceramic with water. The Tensionic tensiometer was then pushed into a hole made with a gouge drill of $30 \mathrm{~mm}$ in diameter and a screw drill of $22 \mathrm{~mm}$ in diameter for the last $100 \mathrm{~mm}$ of the hole. The bottom of this hole was previously filled with a mud made with fine soil extracted below the ploughing layer. Capillary tubes and ceramic cup were then filled with degased distilled water.

\subsection{Fields and cropping systems}

Experiments were conducted in a 400 ha farm located $30 \mathrm{~km}$ east of Montpellier (southeastern France). Five fields were chosen to represent the diversity of the cropping systems in the region: alfalfa-tall fescue association (field 1); succession of canola, annual ryegrass and sunflower (field 2), vineyard intercropped with grass-legume mixture (field 3), field-grown salad (field 4), greenhouse-grown salad (field 5). Fields were also different for soil texture, organic matter content and stone abundance (table I). Fields 1 to 3 were studied during 2 years ( 1994 and 1995) and fields 4 and 5 were studied only during the cropping cycle of the salad crops (winter 1996-1997). Crops were cultivated according to the organic farming rules. They were fertilized with

Table I. Texture, organic matter content and total nitrogen content of the fine soil, and stone content of the bulk soil for the various soil layers of the five fields.

\begin{tabular}{|c|c|c|c|c|c|c|}
\hline $\begin{array}{l}\text { Field and soil } \\
\text { layer } \\
\mathrm{m}\end{array}$ & Clay & Loam & $\begin{array}{c}\text { Sand } \\
\% \text { of fine soil }\end{array}$ & $\begin{array}{c}\text { Organic matter } \\
\%\end{array}$ & $\begin{array}{c}\text { Total N } \\
\% o\end{array}$ & $\begin{array}{l}\text { Stone content } \\
\% \text { of bulk soil }\end{array}$ \\
\hline \multicolumn{7}{|l|}{ Field 1} \\
\hline $0-0.2$ & 33.60 & 46.50 & 19.90 & 2.13 & 1.36 & 17.2 \\
\hline $0.2-0.4$ & 34.30 & 45.50 & 20.20 & 1.49 & 0.95 & 3.5 \\
\hline $0.4-0.9$ & 29.80 & 49.00 & 21.20 & & & 23.1 \\
\hline $0.9-1.2$ & 29.10 & 36.40 & 34.50 & & & 76.5 \\
\hline \multicolumn{7}{|l|}{ Field 2} \\
\hline $0-0.6$ & 15.10 & 38.30 & 46.60 & 1.25 & 0.73 & 71.8 \\
\hline $0.6-1.3$ & 26.40 & 34.70 & 38.90 & 0.70 & 0.52 & 89.6 \\
\hline \multicolumn{7}{|l|}{ Field 3} \\
\hline $0-0.2$ & 29.90 & 53.80 & 16.30 & 1.80 & 1.15 & 10.0 \\
\hline $0.2-0.45$ & 31.40 & 52.30 & 16.30 & 1.48 & 0.92 & 7.8 \\
\hline $0.45-0.65$ & 31.40 & 50.00 & 18.60 & & & 31.6 \\
\hline \multicolumn{7}{|l|}{ Fields 4 and 5} \\
\hline $0-0.3$ & 42.00 & 39.00 & 19.00 & 3.14 & 1.92 & 0.1 \\
\hline
\end{tabular}


organic manures following the nitrogen balance method [29]. Cultural practices are described in table II.

\subsection{Experimental design and measurements}

Field size was 1 to 2 ha, except for field $5\left(650 \mathrm{~m}^{2}\right.$ of unheated greenhouse). Each field had three sites of measurements (A, B and C) located in the centre of the field, with $30 \mathrm{~m}$ between sites ( $10 \mathrm{~m}$ for field 5 ). In each site, two Tensionic tensiometers were inserted in the middle of the inter-row spacing (fields 1 and 2) or on the row (fields 3 to 5), with their ceramic cup below the rooting zone. The upper and lower Tensionic tensiometers were at a depth of 1.0 and $1.5 \mathrm{~m}$, respectively, for deep-rooted crops (fields 1 to 3 ) and at a depth of 0.5 and $0.7 \mathrm{~m}$ for shallow-rooted crops (fields 4 and 5). For grappe (field 3 ) and alfalfa (field 1), higher depth could be required to avoid interaction between ceramic cups and roots, but in our fields, root penetration was limited to $1.0 \mathrm{~m}$ by a calcareous crust. In fields 1 to 3 , Tensionic tensiometers remained in the soil for 2 years and cultural practices were manually reproduced around the measurement sites.

Soil water potential $(\Psi)$ was measured every 10 days, except during rainfall events where it was measured daily. The Tensionic tensiometer solution was extracted every 10 days, stored at $-18{ }^{\circ} \mathrm{C}$ and analysed during the following week. Nitrate was analysed by colorimetric reaction after reduction in nitrite on a cadmium column [16]. Depth of the water table roof was measured every

Table II. Cultural practices applied to the five fields.

\begin{tabular}{|c|c|c|c|c|c|}
\hline Field & Cultivated species & Sowing dates & Sowing density & Fertilization & Irrigation \\
\hline Field 1 & $\begin{array}{l}\text { mixture of: } \\
\text { alfalfa (Medicago sativa } \mathrm{L} .) \\
\text { tall fescue (Festuca elatior } \mathrm{L} .)\end{array}$ & $\begin{array}{l}5 / 11 / 92 \\
5 / 11 / 92\end{array}$ & $\begin{array}{l}5 \mathrm{~kg} \cdot \mathrm{ha}^{-1} \\
10 \mathrm{~kg} \cdot \mathrm{ha}^{-1}\end{array}$ & no fertilization & $\begin{array}{l}30 \mathrm{~mm} \text { on } 1 \text { and } \\
25 / 06 / 94 \\
30 \mathrm{~mm}, 15 / 07 / 94 \\
30 \mathrm{~mm}, 5 / 07 / 95\end{array}$ \\
\hline Field 2 & $\begin{array}{l}\text { - annual ryegrass } \\
\text { (Lolium multiflorum) } \\
\text { - sunflower } \\
\text { (Helianthus annuus) }\end{array}$ & $\begin{array}{l}\text { spontaneous } \\
27 / 03 / 95\end{array}$ & $\begin{array}{l}75 \times 10^{3} \\
\text { seeds.ha }{ }^{-1}\end{array}$ & $\begin{array}{l}40 \mathrm{~kg} \mathrm{~N} \cdot \mathrm{ha}^{-1} \\
\text { (grappe grounds) } \\
\text { 20/02/94 }\end{array}$ & no irrigation \\
\hline Field 3 & $\begin{array}{l}\text { grappe } \\
\text { Vitis vinifera } \mathrm{L} \text { (cv. Grenache) } \\
\text { + intercropped barley } \\
\text { (Hordeum vulgare L.) } \\
\text { + intercropped triticale } \\
\text { and subterranean clover } \\
\text { (Trifolium subterraneum) }\end{array}$ & $\begin{array}{l}\text { 20 years ago } \\
\text { March } 1994 \\
5 / 02 / 95 \\
5 / 02 / 95\end{array}$ & $\begin{array}{l}2600 \\
\text { plants.ha- } \\
\\
80 \mathrm{~kg} \cdot \mathrm{ha}^{-1} \\
10 \mathrm{~kg} \cdot \mathrm{ha}^{-1}\end{array}$ & $\begin{array}{l}30 \mathrm{~kg} \mathrm{~N} \cdot \mathrm{ha}^{-1} \\
20 \mathrm{~kg} \mathrm{P} \mathrm{O}_{5} \cdot \mathrm{ha}^{-1} \\
40 \mathrm{~kg} \mathrm{~K} \mathrm{~K}_{2} \mathrm{O} \cdot \mathrm{ha}^{-1} \\
\text { (bird guano) } 15 / 12 / 94\end{array}$ & no irrigation \\
\hline Field 4 & endivia (Chicorium endivia) & $10 / 09 / 96$ & $\begin{array}{l}45 \times 10^{3} \\
\text { plants.ha }{ }^{-1}\end{array}$ & $\begin{array}{l}120 \mathrm{~kg} \mathrm{~N} \cdot \mathrm{ha}^{-1} \\
240 \mathrm{~kg} \mathrm{P} \mathrm{O}_{5} \cdot \mathrm{ha}^{-1} \\
360 \mathrm{~kg} \mathrm{~K} \mathrm{O}_{2} \cdot \mathrm{ha}^{-1} \\
\text { (organic fertilizer) 16/08/96 }\end{array}$ & $\begin{array}{l}40 \mathrm{~mm} \text { after } \\
\text { planting }\end{array}$ \\
\hline Field 5 & lettuce (Lactuca sativa L.) & $2 / 12 / 96$ & $\begin{array}{l}140 \times 10^{3} \\
\text { plants.ha- }{ }^{-1}\end{array}$ & $\begin{array}{l}\text { as field } 4 \\
27 / 11 / 96\end{array}$ & $\begin{array}{l}40 \mathrm{~mm} \text { after } \\
\text { planting }\end{array}$ \\
\hline
\end{tabular}


10 days on piezometers located near each field. A sample of water was then extracted and analysed for nitrate content (DIREN Languedoc-Roussillon, pers. comm.).

\section{RESULTS}

\subsection{Water potential} and nitrate content of the soil solution

The evolution with time of soil water potential ( $\Psi)$ was similar for the three sites of measurement of a field, despite differences in absolute values between sites, for some dates of measurement (not shown). Similar results were obtained for nitrate content of the soil solution (not shown). Each field can then be represented with the evolution of the mean of the measurements made at the three sites, despite the high values of standard deviation of this mean for some dates of measurement (figures $1 a, b$ and $3 b$ ). Fields 1 to 3 showed, every year, a winter phase with high $\Psi$ and a spring phase of rapid reduction of $\Psi$ when the evaporative demand increased (figure la). The lower limit of Tensionic tensiometer functioning ( -65 to $-80 \mathrm{kPa}$ depending on the field) was reached in June every year. On field 1, site B had a particular behaviour at the end of the second year: water potential at $1.5 \mathrm{~m}$ deep remained around $-17 \mathrm{kPa}$ between days 426 and 457 (not shown). This explains the increase in the standard deviation at this period (figure $1 a$ ). The particular behaviour of this site could be explained by the disappearance of alfalfa and its replacement by tall fescue with a more shallow root system. Below salad crops (figures $2 a$ and $3 a$ ) $\Psi$ remained at high values $(>-20 \mathrm{kPa})$ during the whole plant cycle.

Nitrate content of the soil solution $\left(\mathrm{CNO}_{3}^{-}\right)$ remained at low values during the 2 years for the alfalfa-fescue association (figure $l b$ ), as for field crops and vineyards (not shown). It remained below $20 \mathrm{mg} \mathrm{NO}{ }_{3}^{-} \mathrm{L}^{-1}$, which is very low compared to similar species grown with high level of nitrogen fertilization (from 32 to $126 \mathrm{mg} \mathrm{NO}{ }_{3}^{-} \cdot \mathrm{L}^{-1}$, in the study of Benoît et al. [5]). On the other hand, the soil solution had a high nitrate content below the salad crop, especially after planting (between 75 and $275 \mathrm{mg} \mathrm{NO}{ }_{3}^{-} \cdot \mathrm{L}^{-1}$ depending on measurement sites and depth). In field-grown salads (figure $2 b$ ) $\mathrm{CNO}_{3}{ }^{-}$rapidly fell to values lower than $50 \mathrm{mg}$ $\mathrm{NO}_{3}^{-} \cdot \mathrm{L}^{-1}$ at harvest. This was not the case for greenhouse-grown salads (figure $3 b$ ) for which $\mathrm{CNO}_{3}^{-}$remained between 100 and $200 \mathrm{mg}$ $\mathrm{NO}_{3}^{-} \cdot \mathrm{L}^{-1}$.

In field 1 (figure $1 b$ ), we observed, on the three sites, an unexpected peak of $\mathrm{CNO}_{3}^{-}$at $1.5 \mathrm{~m}$ deep between days 315 and 342 . This peak is difficult to explain with leaching and mineralization processes, because $\mathrm{CNO}_{3}^{-}$was almost constant at $1.0 \mathrm{~m}$ deep. Piezometric measurements suggest that it resulted from the rising of the water table. The water table roof was indeed at $1.0 \mathrm{~m}$ below the soil surface between days 268 and 317 and this water table had a nitrate content of $70 \mathrm{mg} \mathrm{NO}{ }_{3}^{-} \cdot \mathrm{L}^{-1}$.

\subsection{Direction of the water flow below the rooting zone}

The periods of drainage below the rooting zone were identified as the periods of positive gradient of soil water potential between the two depths of measurement (see section 2). On fields 1 (figure Ic) and 5 (figure $3 c$ ), the evolution with time of this gradient was similar for the three sites of measurement, allowing the calculation of a mean value of the gradient. In field 4 (figure 2c), site A was analysed separately because it frequently showed a gradient with an opposite sign compared to the two other sites.

Field 1 experienced a period of drainage between November and March, as shown by the positive gradients during this period (figure $1 c$ ). This is explained by the excess of water (compared to the storage capacity of the 0 to $1.0 \mathrm{~m}$ soil layer) induced by heavy rainfall and low evaporative demand during this period. The sign of the gradient became negative when the water extraction by the plant increased in spring (days 59 and 390, figure 1c). The water was then moving from 1.5 to $1.0 \mathrm{~m}$ until the resumption of heavy rains in November. In field-grown salads, winter rainfall, combined with irrigation, led to a continuous drainage during the 
a) Soil Water potential

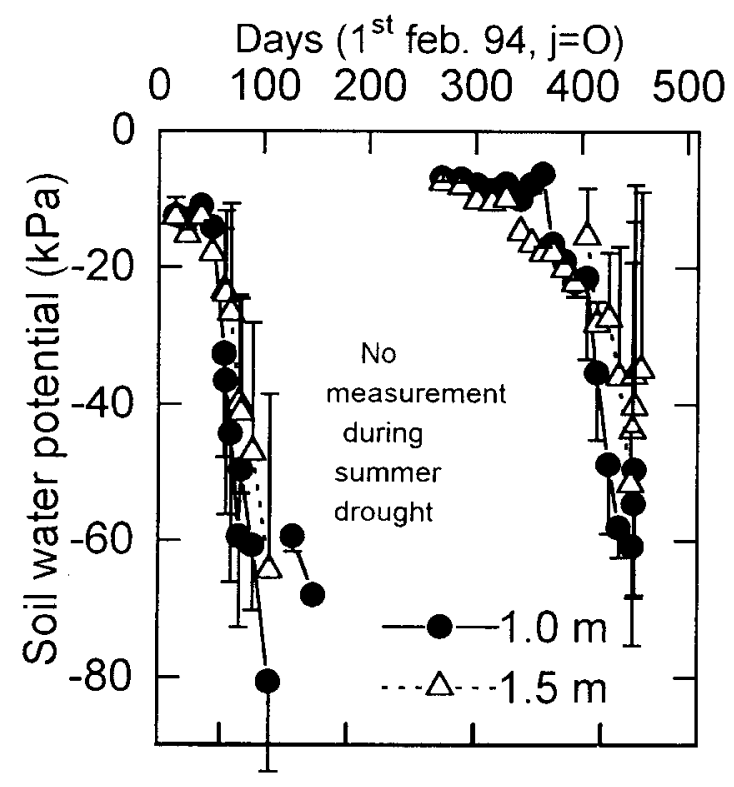

c) Hydraulic Gradient

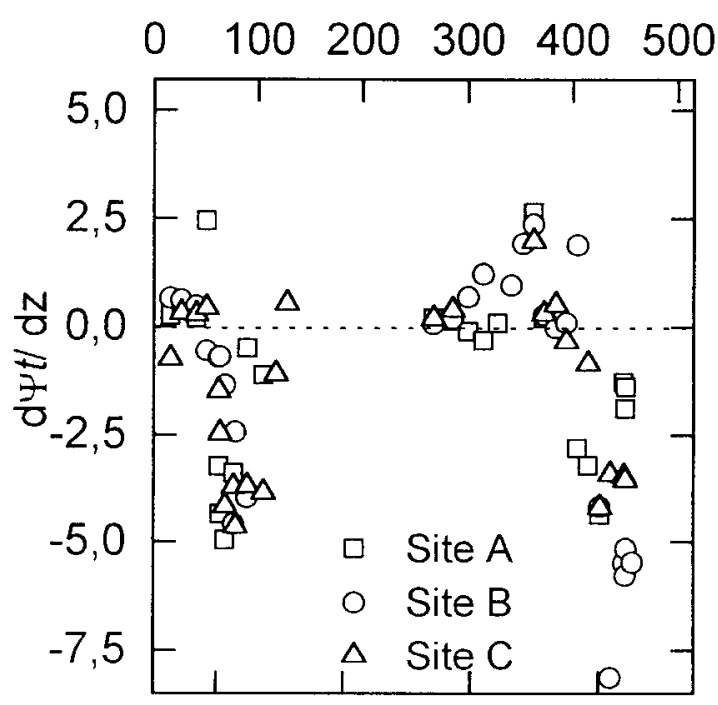

Apr. 94 Aug. 94 Dec 94 Apr. 95 b) Soil Nitrate Concentration

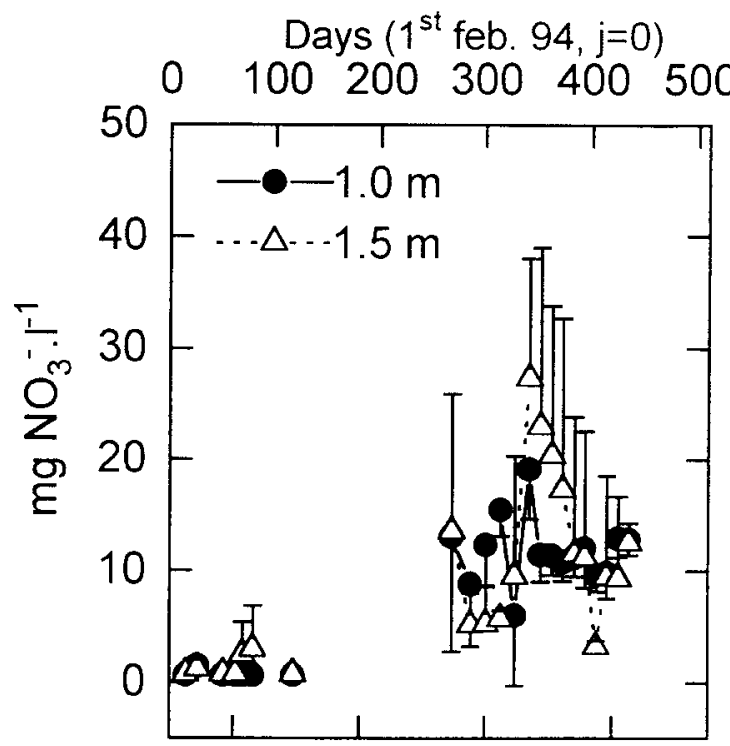

d) Nitrate Leaching Risk Indicator

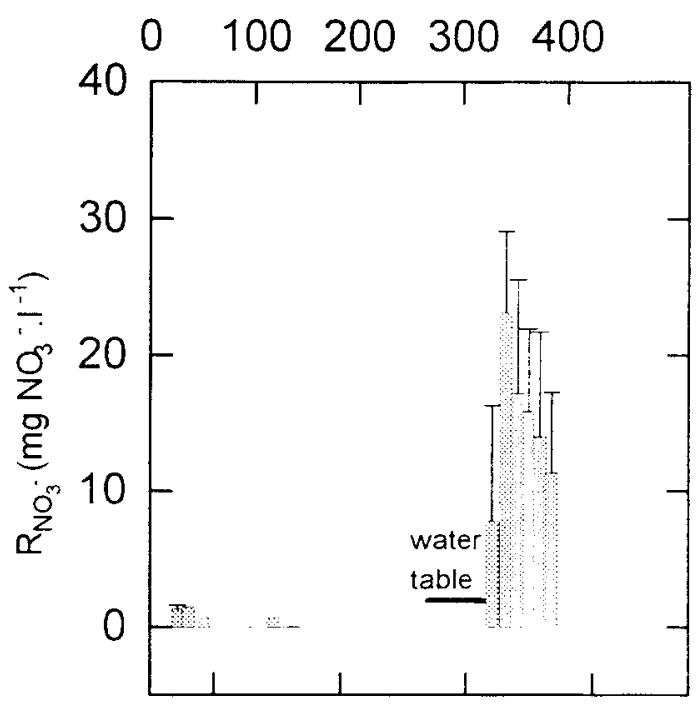

Apr. 94 Aug. 94 Dec. 94 Apr 95

Figure 1. Evolution with time of soil water potential (a), nitrate concentration of the soil solution (b), hydraulic gradient (c) and nitrate leaching risk indicator $\left(\mathrm{RNO}_{3}^{-}, \mathrm{d}\right.$ ) below the rooting zone of an alfalfa-fescue crop (field 1). $\mathrm{RNO}_{3}^{-}$was calculated with data from figures $b$ and $c$, as described in section 2. Each value in figures $a, b$ and $d$ is the average of the three sites of measurement. Figure $c$ shows the individual values of the three sites, for the hydraulic gradient between 1.0 and $1.5 \mathrm{~m}$ deep. 
a) Soil Water potential

Days after planting

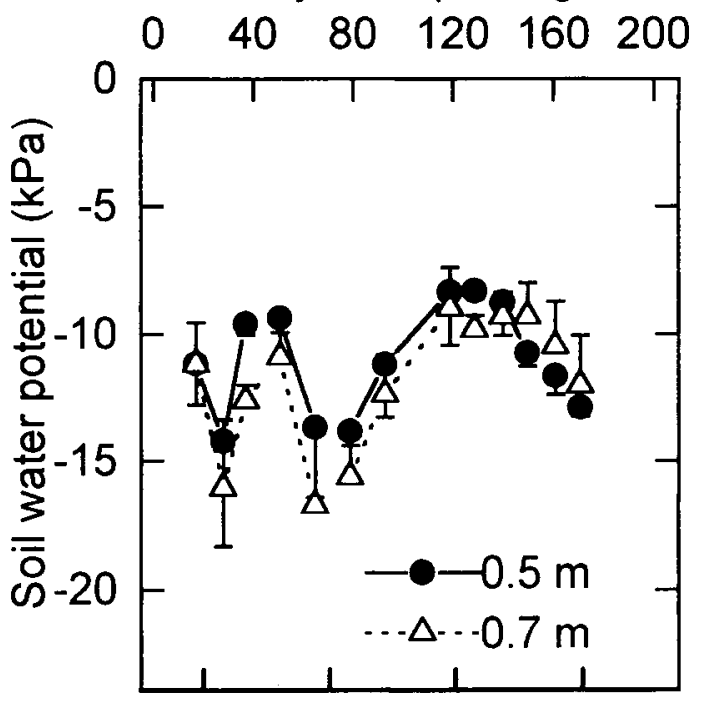

c) Hydraulic Gradient

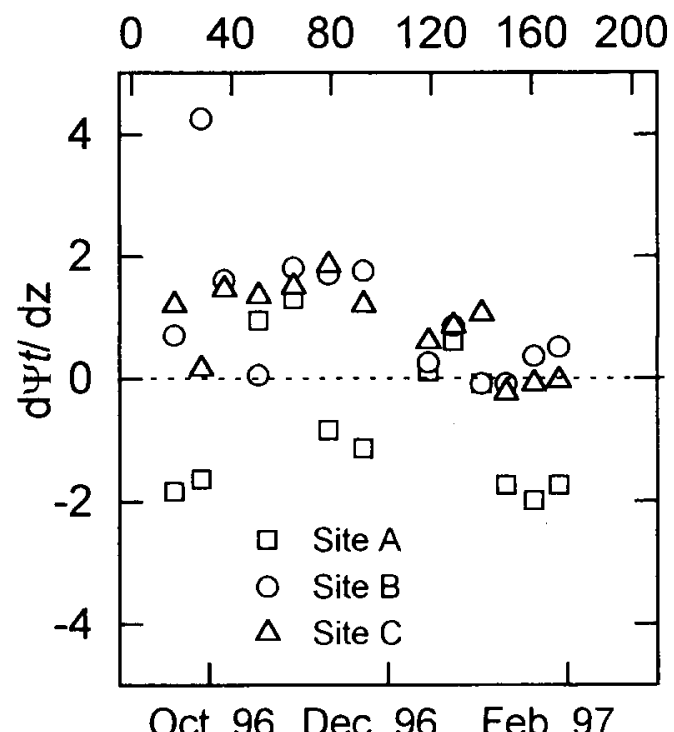

b) Soil Nitrate Concentration

Days after planting

$\begin{array}{llllll}0 & 40 & 80 & 120 & 160 & 200\end{array}$

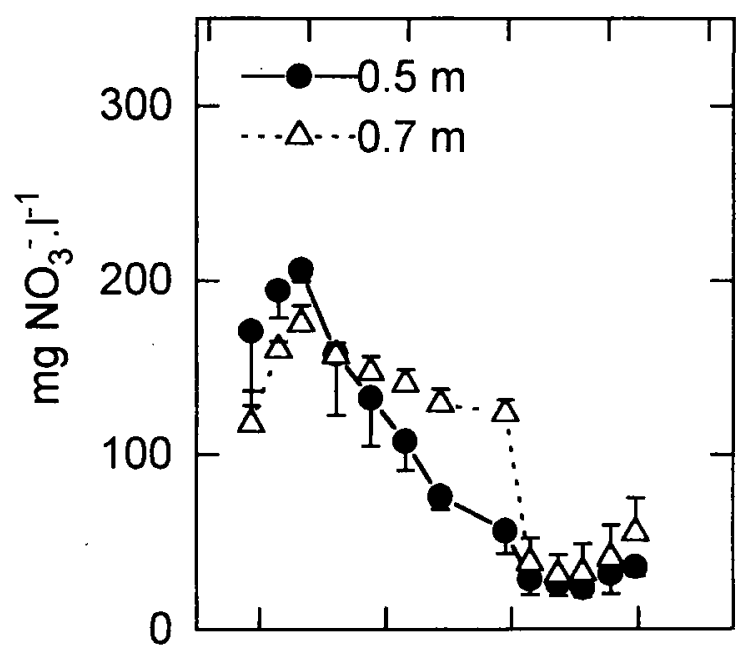

d) Nitrate Leaching Risk Indicator

$\begin{array}{llllll}0 & 40 & 80 & 120 & 160 & 200\end{array}$

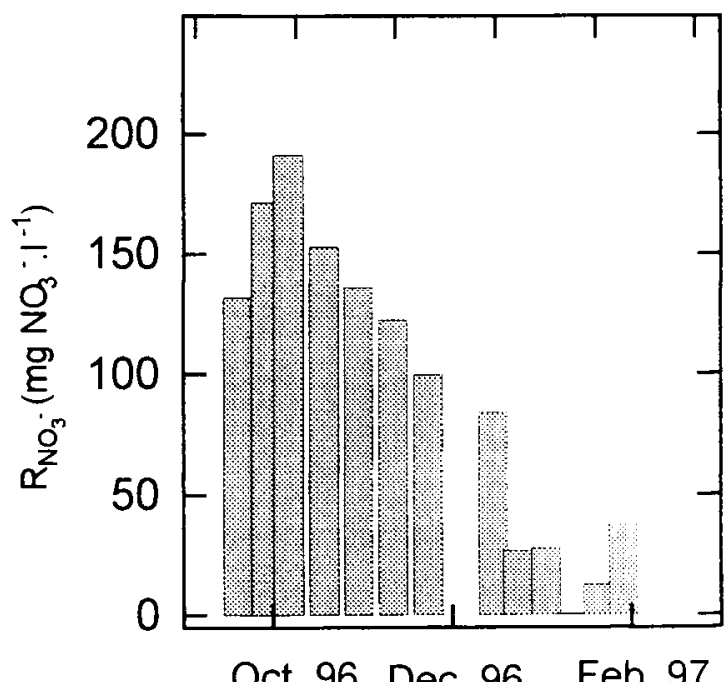

Figure 2. Evolution with time of soil water potential (a), nitrate concentration of the soil solution (b), hydraulic gradient (c) and nitrate leaching risk indicator $\left(\mathrm{RNO}_{3}^{-}\right.$, d) below the rooting zone of a field-grown salad crop (field 4). $\mathrm{RNO}_{3}^{-}$was calculated with data from figures $b$ and $c$, as described in section 2. Each value is the average of the three sites of measurement (figures $a$ and $b$ ) or of sites $\mathrm{B}$ and $\mathrm{C}($ figure $d$ ). Figure $c$ shows the individual values of the three sites, for the hydraulic gradient between 0.5 and $0.7 \mathrm{~m}$ deep. 
a) Soil Water potential

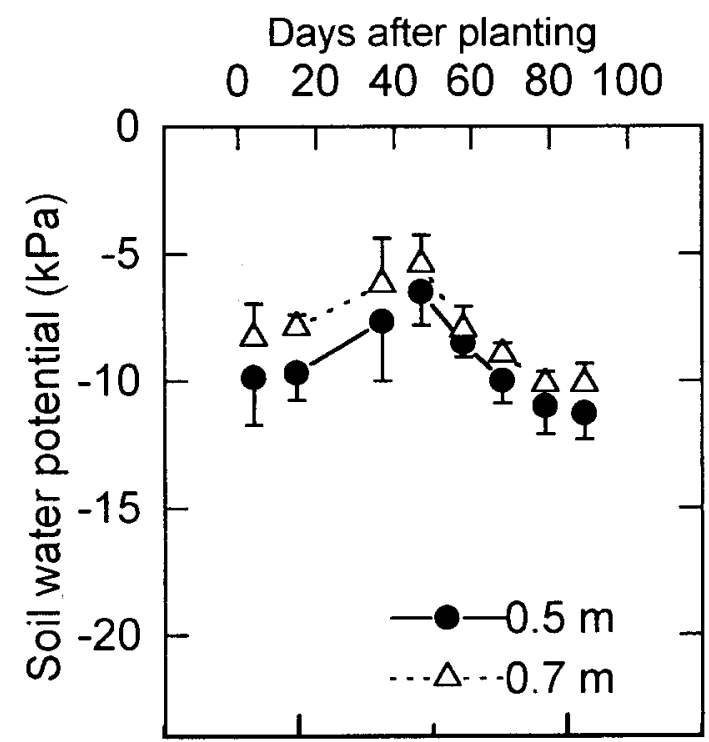

c) Hydraulic Gradient

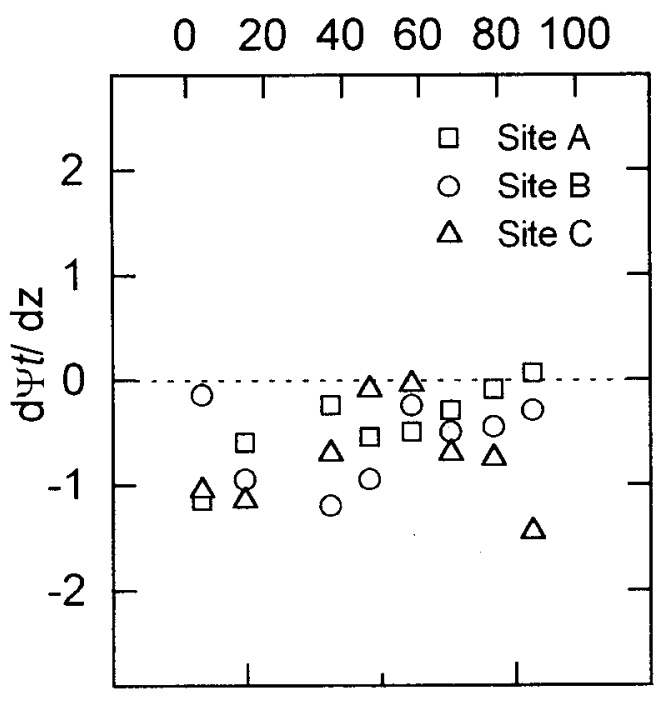

Dec. $96 \quad$ Jan. 97 Feb. 97

\section{b) Soil Nitrate Concentration}

Days after planting

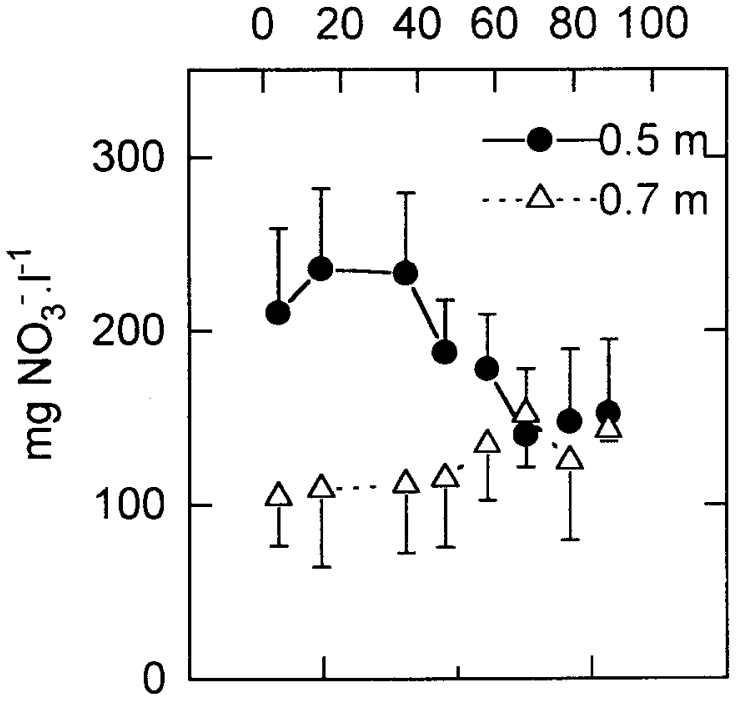

d) Nitrate Leaching

Risk Indicator

020406080100

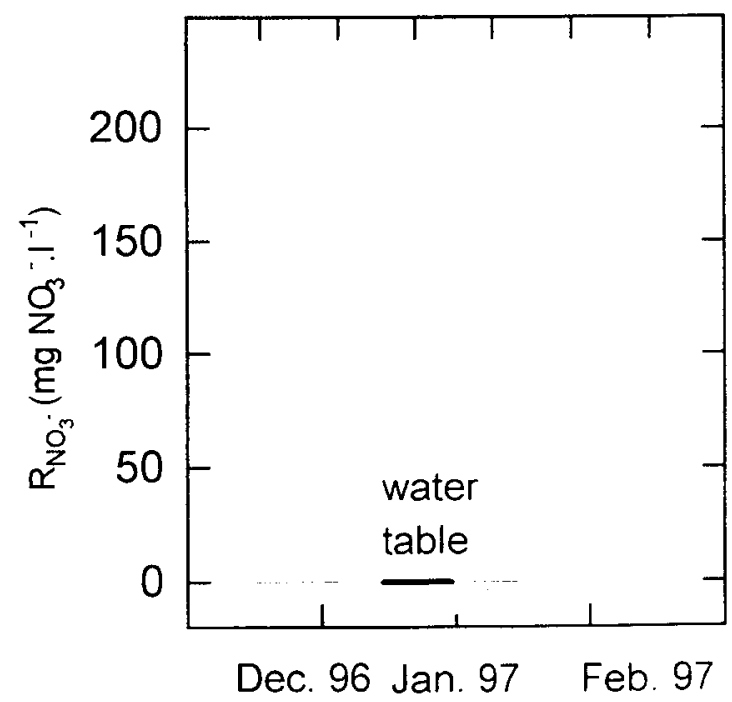

Figure 3. Evolution with time of soil water potential (a), nitrate concentration of the soil solution (b), hydraulic gradient (c) and nitrate leaching risk indicator $\left(\mathrm{RNO}_{3}{ }^{-}\right.$, d) below the rooting zone of a greenhouse-grown salad crop (field 4). $\mathrm{RNO}_{3}{ }^{-}$was calculated with data from figures $b$ and $c$, as described in section 2. Each value in figures $a, b$ and $d$ is the average of the three sites of measurement. Figure $c$ shows the individual values of the three sites, for the hydraulic gradient between 0.5 and $0.7 \mathrm{~m}$ deep. 
whole cycle, at least for sites B and C (figure $2 b$ ). Conversely, in greenhouse-grown salads, the water was moving from 0.7 to $0.5 \mathrm{~m}$ (negative gradient) during the entire crop cycle (figure $3 c$ ).

In field 1, the hydraulic gradient remained close to zero during a long period (days 268 to 333, figure $1 \mathrm{c}$ ), indicating the occurrence of a zero flow plan or a water table between 1.0 and $1.5 \mathrm{~m}$ deep. As soil water potential remained above $-10 \mathrm{kPa}$ during this period (figure la), we can conclude that soil matric potential was null. This indicates that soil was saturated with water between 1.0 and $1.5 \mathrm{~m}$ deep. Piezometric measurements have confirmed that the water table roof rose to $1.0 \mathrm{~m}$ below the soil surface during this period (not shown). Similarly, the removal of the water table from the soil surface in January 1995 can explain the reduction of soil water potential from -10 to $-15 \mathrm{kPa}$ during this period (days 334 to 358 ). The same situation was observed in field 5 between days 30 and 60: soil water potential suggested a saturated soil at $0.7 \mathrm{~m}$ deep $(\Psi>-7 \mathrm{kPa}$, figure $3 \mathrm{c})$ and piezometric measurements indicated that the water table roof was at $0.6 \mathrm{~m}$ below the soil surface (not shown). Conversely, when piezometric measurement showed that the water table roof remained at more than $1.5 \mathrm{~m}$ below soil surface, we did not observe this situation of high soil water potential and null gradient (field 2, not shown).

\subsection{Analysis of nitrate leaching risk}

The indicator of nitrate leaching risk $\left(\mathrm{RNO}_{3}{ }^{-}\right)$ was calculated for each field, as described in section 2. When $\mathrm{RNO}_{3}^{-}$has a positive value it indicates the nitrate concentration of the water drained below the rooting zone. $\mathrm{RNO}_{3}^{-}$was calculated at a 10 day timestep, using the mean hydraulic gradient and the mean nitrate concentration of the soil solution for the three sites. If one of the sites had a gradient with an opposite sign compared to the others (site A in figure $2 c$ ), this site was considered individually for the calculation of $\mathrm{RNO}_{3}^{-}$.

For the alfalfa-fescue association (field 1), $\mathrm{RNO}_{3}^{-}$remained at a very low level $(<5 \mathrm{mg}$
$\mathrm{NO}_{3}{ }^{-} \cdot \mathrm{L}^{-1}$ ) in 1994 (figure 1 d). It was equal to zero after the end of March, except for a 10 day period of drainage induced by an irrigation in June. In 1995, $\mathrm{RNO}_{3}{ }^{-}$had higher values but they remained below $25 \mathrm{mg} \mathrm{NO}{ }_{3}^{-} . \mathrm{L}^{-1}$, which is still half of the threshold value for drinking water. These results give confirmation that the nitrate leaching risk is reduced below a perennial forage crop with a complete soil covering during fall and winter and with an active growth in the beginning of spring.

For the vineyard (field 3), $\mathrm{RNO}_{3}^{-}$was higher than in field 1 in 1994 (figure 4a), because the barley intercrop was sown too late (March 1994) to reduce the drainage. An earlier sowing (fall of 1993) would have been required but access to the field was impaired by the heavy rainfall of this period. In 1995 the spontaneous cover crop which was grown after the grape harvest had a significant effect on nitrate leaching because it reduced the $\mathrm{RNO}_{3}{ }^{-}$values compared to 1994 . Over the 2 years, this vineyard field had a longer period of drainage (indicated by positive values of $\mathrm{RNO}_{3}{ }^{-}$) compared with the alfalfa-fescue field (figure $I d$ ). Nevertheless, the risk of nitrate leaching was very low because $\mathrm{RNO}_{3}{ }^{-}$remained below $30 \mathrm{mg}$ $\mathrm{NO}_{3}{ }^{-} \cdot \mathrm{L}^{-1}$ in 1994 and below $15 \mathrm{mg} \mathrm{NO}_{3}^{-} \cdot \mathrm{L}^{-1}$ in 1995 (figure 4a).

Field 2 (figure $4 b$ ) was almost continuously covered during the 2 years by the three successive crops. This reduced the period of drainage compared to fields 1 and 3 and the nitrate concentration of the drained water remained below $5 \mathrm{mg}$ $\mathrm{NO}_{3}{ }^{-} \cdot \mathrm{L}^{-1}$. This gives confirmation of the efficiency of the ryegrass crop $[22,21]$ and the oilseed crops (canola and sunflower) in the reduction of drainage and in the uptake of mineral nitrogen.

For the field-grown salad (field 4), $\mathrm{RNO}_{3}^{-}$was calculated for sites B and C (figure $2 d$ ), because site A showed an opposite gradient compared to these sites (figure 2c). $\mathrm{RNO}_{3}^{-}$was almost continuously positive because drainage was occurring throughout the whole cycle of the crop, i.e. for 5 months. Conversely no drainage occurred for the greenhouse-grown salad (figure $3 d$ ), because the hydraulic gradient was maintained at negative values from planting to harvest (figure $3 c$ ). $\mathrm{RNO}_{3}^{-}$ 


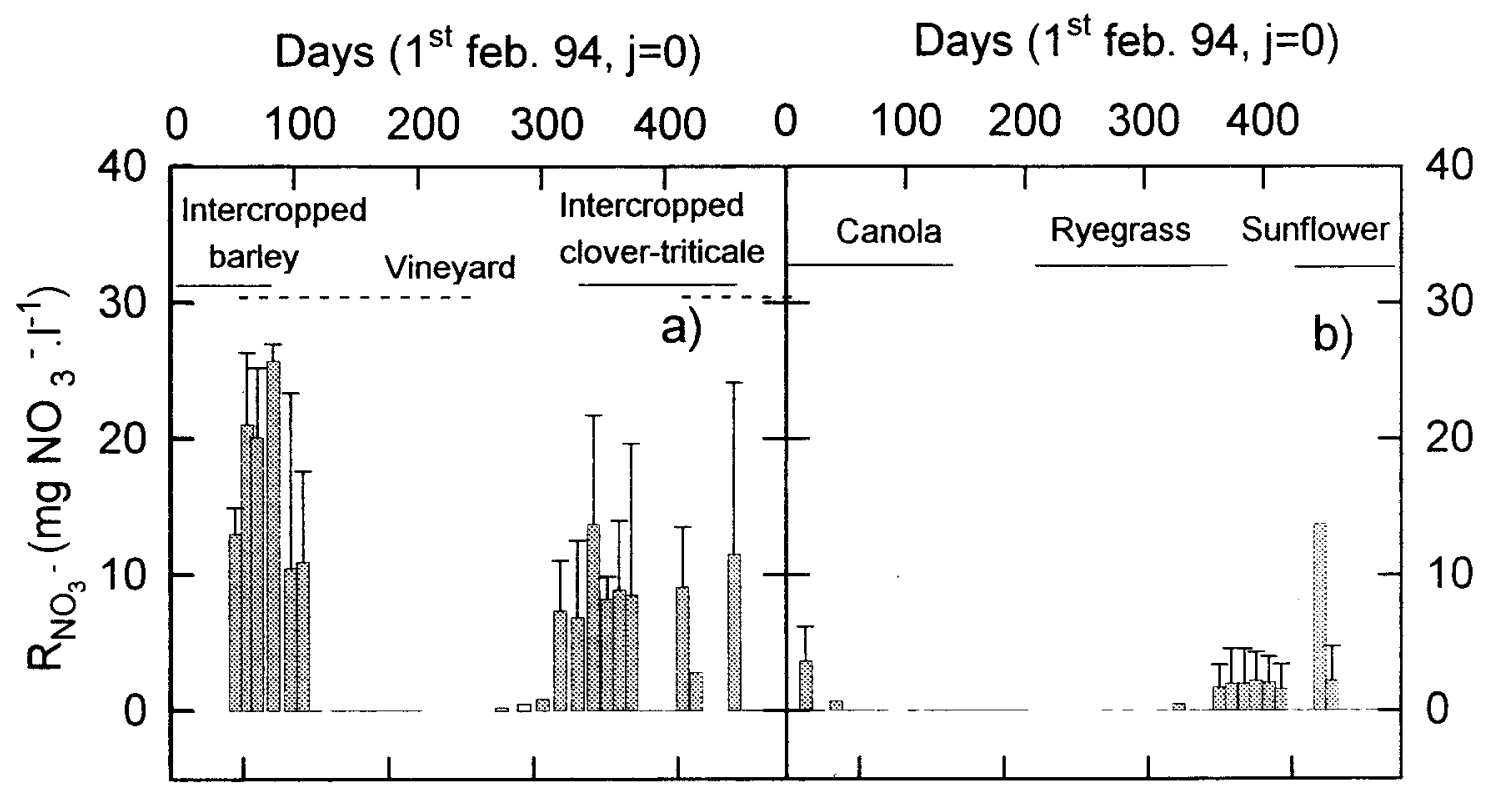

Apr. 94 Aug. 94 Dec. 94 Apr. 95 Apr. 94 Aug. 94 Dec. 94 Apr. 95

Figure 4. Evolution with time of the nitrate leaching risk indicator $\left(\mathrm{RNO}_{3}^{-}\right)$for an intercropped vineyard (a, field 3$)$ and a 2 year succession of canola-ryegrass-sunflower (b, field 2). $\mathrm{RNO}_{3}{ }^{-}$was calculated, as described in section 2 , from measurements of soil water potential and nitrate concentration of the soil solution at 1.0 and $1.5 \mathrm{~m}$ deep. Each value is the average of the three sites of measurement.

remained at zero for this salad crop (figure $3 d$ ). This avoidance of nitrate leaching risk during the crop was made possible by the control of the water supply in greenhouse-grown salads: no rainfall and irrigation scheduled from soil water content.

\section{DISCUSSION}

\subsection{Measurement of water potential and nitrate content of the soil solution in farmers' fields}

Tensionic tensiometers were used in five contrasted cropping systems to measure soil water potential and nitrate content of the soil solution. The absolute values and the evolution with time and depth of these two variables are consistent with previously published results. Nitrate content of the drained water was very low in forage crops (figure $1 b$ ), intercropped vineyards (figure $4 a$ ) and field crop rotation with nitrate catch-crop of ryegrass (figure $4 b$ ) as shown by many authors [5, 21, 22]. The high level of nitrate measured in the soil solution below salad crops (figures $2 b$ and $3 b$ ) was also similar to those obtained by Bruckler et al. [9] in field-grown salads of the same region.

Despite the spatial variability of the amount of mineral nitrogen within a field [9], the evolution with time of nitrate content of the soil solution at a given depth $\left(\mathrm{CNO}_{3}^{-}\right)$, was similar for the three measurement sites of a field (figures $l b, 2 b$ and $3 b$ ). The same conclusion can be drawn for soil water potential ( $\Psi$, figures $1 a, 2 a$ and $3 a$ ). In these conditions each field can be characterized with the mean values of $\Psi$ or $\mathrm{CNO}_{3}^{-}$calculated with only three sets of two Tensionic tensiometers placed in an area representative of the field. The sites must be placed on the dominant soil type and where the crop stand is 
representative of the field (crop density and growth rate). Similar conclusions have been obtained for $\Psi$ in an irrigated maize crop [25]. Spatial variability of nitrate content may be higher in cropping systems receiving large amounts of mineral nitrogen. This would imply an increase in the number of measurement sites, with a simultaneous increase in the cost of the diagnosis. For example Benoît et al. [5] used seven ceramic cups per depth of measurement to characterize nitrate leaching in a farmer's field. If the field is made up of several soil types or if there is a gradient in the amount of water or nitrogen applied, the field must be divided into sub-units before applying the diagnosis approach. For example, particular evolution of $\Psi$ in site A of fields 1 (figure $1 a$ ) and 4 (figure 2a) was explained by the canopy characteristics (suppression of alfalfa in the association) and the heterogeneity in water supply by the irrigation system, respectively.

\subsection{Calculation of a nitrate leaching risk indicator}

The two variables given by the Tensionic tensiometer $\left(\Psi\right.$ and $\left.\mathrm{CNO}_{3}^{-}\right)$allowed the calculation of a nitrate leaching risk indicator $\left(\mathrm{RNO}_{3}^{-}{ }_{\mathrm{j}}\right)$ which gives the periods of drainage during the crop cycle and the nitrate concentration of the drained water (see section 2). It showed that the risk of nitrate leaching was negligible for the alfalfa-fescue association (figure $1 d$ ), intercropped vineyards (figure $4 a$ ) and field crop rotations with nitrate catch-crop (figure $4 b$ ), despite the long period of drainage below these crops. On the other hand, nitrate content of the soil solution below salad crops (figures $2 b$ and $3 b$ ) was at least four times higher than for the other crops (> $100 \mathrm{mg} \mathrm{NO}_{3}^{-} \cdot \mathrm{L}^{-1}$ during most of the crop cycle). The risk of nitrate leaching during the crop was important in field-grown salad figure $2 d$ ) because winter rainfall and excessive irrigation induced a continuous drainage from plantation to harvest. This risk was negligible below the greenhouse-grown salads (figure $3 d$ ) because drainage was avoided by the absence of rainfall and a scheduling of irrigation from soil water status. Nevertheless, the amount of nitrate left in the soil at harvest was very high, as suggested by the high nitrate content (figure $3 b$ ) of a soil at field capacity $(\Psi>-10 \mathrm{kPa}$ in figure $3 a$ ). This would induce a high risk of nitrate leaching after the salad crop if no deep rooted nitrate catch-crop is sown.

The $\mathrm{RNO}_{3}^{-} \mathbf{j}$ indicator must be used with caution when comparing fields with less contrasted nitrate concentrations than in the above examples. $\mathrm{RNO}_{3}^{-} \mathrm{j}$ does not give the amount of nitrate leached below the rooting zone $\left[\mathrm{QNO}_{3}{ }^{-}\right.$in equation (1)], but only the nitrate concentration of the soil solution during the periods of drainage. Comparing values of $\mathrm{RNO}_{3}^{-}$of different fields implies the assumption that the amount of water drained below the rooting zone $\left(\mathrm{QH}_{2} \mathrm{O}\right)$ is similar for these fields. Theoretically $\mathrm{QH}_{2} \mathrm{O}$ can be calculated with Darcy's law from the hydraulic gradient given in equation (2). Nevertheless this would imply the assumption that the hydraulic gradient varies linearly between the two depths of measurement, which is not necessarily the case when the distance between these two measurements is larger than $0.2 \mathrm{~m}$. On the other hand, equation (2) requires the determination of the relationship between soil hydraulic conductivity and soil water potential $[\mathrm{K}(\Psi)]$ for each field where the diagnosis has to be applied. The parameters of this relationship can be estimated from soil characteristics such as texture, carbon content and bulk density [34]. Nevertheless, the precision of this method is too low to avoid the experimental determination of the $\mathrm{K}(\Psi)$ parameters [33]. $\mathrm{QH}_{2} \mathrm{O}$ could also be calculated with a simulation model of water balance in the rooting zone [13], but this implies having a model validated for the amount of water drained, for each crop and each soil concerned by the diagnosis. These requirements make it difficult and costly to use this quantitative approach in a large number of farmers' fields. As a first step, use of the qualitative indicator $\mathrm{RNO}_{3}^{-}$j seems more realistic for a rapid diagnosis in farmers' fields on crops and soils for which the knowledge is limited.

\subsection{Additional information given by the Tensionic tensiometer: position of the water table roof}

Measurements of $\Psi$ at two depths and the calculation of the hydraulic gradient showed that the 
water table was sometimes rising into the measurement zone, in agreement with piezometric measurements. This was the case after the heavy rainfall of November 1994 in field 1 as shown by the null values of the gradient (figure 1c) combined with $\Psi$ higher than $-10 \mathrm{kPa}$ at $1.0 \mathrm{~m}$ deep and $-15 \mathrm{kPa}$ at $1.5 \mathrm{~m}$ deep (figure la). A similar situation was observed in greenhouse-grown salads in January 1997 (figures 3a). In this case the nitrate content of the soil solution measured with the Tensionic tensiometer was close to the nitrate content of the water table. This information must be integrated in the diagnosis (figures $1 d$ and $3 d$ ) because a water table in contact with the root system can significantly contribute to the water and nitrogen budget of the crop. In greenhouse-grown salads, for example, the water table was shallow enough to maintain soil water content around field capacity in the crop rooting zone.

\section{CONCLUSION}

The Tensionic tensiometer allowed the measurement of soil water potential and nitrate concentration of the soil solution in farmers' fields for a large range of soil types and cropping systems. The contrasted situations presented in this study show that these two variables are required to characterize the risk of nitrate leaching. As a first step in a diagnosis approach, a qualitative indicator of nitrate leaching can be calculated from the Tensionic tensiometer measurements, in the absence of other information on soil, climate and crop. It gives the periods of drainage during the crop cycle and the nitrate content of the drained water at a 10 day timestep. It also indicates whether a water table is contributing to the crop water and nitrogen balance. This indicator can be used to compare cropping systems, crops or cropping techniques for the risk of nitrate leaching. It could also be used to help the farmers to follow the impact of a modification of their cropping system on the risk of groundwater pollution by nitrate. The calculation of a quantitative variable (amount of nitrate leached) could also be made from the Tensionic tensiometers on fields where information is available on soil hydraulic conductivity or for which a water balance has been validated.

This diagnosis on the environmental risk could be associated with a diagnosis on the risk of nitrogen and water stress for the crop, in order to help the farmers to adapt their cropping systems with reference to both environmental and agronomic risks. This requires addition of a third Tensionic tensiometer in each measurement site, in the soil layer with maximal root density (for example $0.2 \mathrm{~m}$ for a salad crop). The two variables given by the Tensionic tensiometer could then be used as a measurement of the nitrogen and soil water status as it is sensed by the crop. This approach is under investigation in vegetable crops (Gay and Wery, unpublished).

Acknowledgements: Technical assistance of Yvan Poirot, manager of the SARL du Mas Faget, and financial support from Perrier-Vittel are gratefully acknowledged. We thanks Anne Laurent (DIREN Languedoc-Roussillon) for the supply of piezometric data and the reviewers for their fruitful corrections of the manuscript.

\section{REFERENCES}

[1] Addiscott T.M., A simple computer model for leaching in structured soils, J Soil Sci. 28 (1977) 554-563.

[2] Addiscott T.M., Wagenet R.J., Concepts of solute leaching in soils: a review of modeling approches, J. Soil Sci. 36 (1985) $411-424$.

[3] Barry D.A.J., Goorahoo D., Goss M.J., Estimation of nitrate concentrations in groundwater using a whole farm nitrogen budget, J. Environ. Qual. 22 (1993) $767-775$.

[4] Benoît M., Un indicateur des risques de pollution azotée nommé « BASCULE 》 (Balance Azotée Spatialisée des systèmes de CULture de l'Exploitation), Fourrages 129 (1992) 95-110.

[5] Benoît M., Saintot D., Gaury F., Mesures en parcelles d'agriculteurs des pertes en nitrate. Variabilité sous divers systèmes de culture et modélisation de la qualité de l'eau d'un bassin d'alimentation, C. R. Acad. Agric. Fr. 81 (1995) 175-188. 
[6] Bergstrom L., Leaching of dichlorprop and nitrate in structured soil, Environ. Pollut. 87 (2) (1995) 189-195.

[7] Bergstrom L., Jarvis N.J., Prediction of nitrate leaching losses from arable under different fertilization intensities using the SOIL-SOILN models, Soil Use Manage. 7 (1991) 79-84.

[8] Bergstrom L., Johnsson H., Torstensson G., Simulation of soil nitrogen dynamics using the SOILN model, Fertil. Res. 27 (1991) 181-188.

[9] Bruckler L., de Cockborne A.M., Renault P., Claudot B., Spatial and temporal variability of nitrate in irrigated salad crops, Irrig. Sci. 17 (1997) 53-61.

[10] Burns I.G., A model for predicting the redistribution of salts applied to fallow soils after excess rainfall or evaporation, J. Soil Sci. 25 (1974) 165-178.

[11] Cameron K.C., Wild A., Prediction of solute leaching under field conditions: an appraisal of three methods, J. Soil Sci. 33 (1982) 659-669.

[12] Catchpoole V.R., Nitrogen dynamics of oats, sorghum, black gram, green panic and lucerne on a clay soil in south-eastern Queensland, Aust. J. Exp. Agric. 32 (1992) 1113-1120.

[13] De Cockborne A.M., Bruckler L., Augé G., Estimation des bilans hydrique et azoté : le cas d'une petite région agricole maraîchère méditerranéenne (Gard), Sécheresse 6 (1995) 189-200.

[14] Gaury F., Benoît M., Modélisation de là qualité des eaux souterraines; influence de l'occupation du sol en situations karstiques de Lorraine, Cah. Cellule Environ. Inra 4 (1992) 77-80.

[15] Guillard K., Griffin G.F., Allinson D.W., Yamartino W.R., Rafey M.M., Pietrrzyk S.W., Nitrogen utilization of selected cropping systems in the U.S. Northeast: II. Soil profile nitrate distribution and accumulation, Agron. J. 87 (1995) 199-207.

[16] Henriksen A., Semer-Olsen A.R., Automatic methods for determining nitrate and nitrite in water and soil extracts, Analyst 95 (1970) 514-518.

[17] Jemison J.M. Jr., Jabro J.D., Fox R.H., Evaluation of LEACHM: II. Simulation of nitrate leaching from nitrogen-fertilized and manured crop, Agron. J. 86 (1994) 852-859.

[18] Kemppainen E., Leaching and uptake of nitrogen and phosphorus from cow slurry and fox manure in a lysimeter trial, Agric. Sci. Finland 4 (1995) 363-375.

[19] Lafolie F., Modélisation des transferts d'azote et possibilité d'application grâce à l'utilisation des données de la lysimétrie, C. R. Acad. Agric. Fr. 81 (1995) $101-119$.

[20] Lafolie F., Bruckler L., de Cockborne A.M., Laboucarié C., Modeling the water transport and nitrogen dynamics in irrigated salad crops, Irrig. Sci. 17 (1997) 95-104.

[21] Machet J.M., Mary B., Effet de différentes successions culturales sur les risques de perte en nitrate en région de grande culture, in: Calvet $\mathrm{R}$. (Ed.), Colloque « Nitrates, Agriculture, Eau », Inra, Paris, 1990, pp. 395-403.

[22] Martinez J., Guiraud G., A lysimeter study of the effects of a ryegrass catch crop, during a winter wheat/maize rotation, on nitrate leaching and on the following crop, J. Soil Sci. 41 (1990) 5-16.

[23] Meisinger J.J., Randall G.W., Estimating nitrogen budgets for soil-crop systems, in: Follett R.F., Keeney D.R., Cruse R.M. (Eds.), Managing Nitrogen for Groundwater Quality and Farm Profitability, SSSA, Inc. Madison, Wisconsin, USA, 1991, pp. 85-124.

[24] Meinardi C.R., Beusen A.H.W., Bollen M.J.S., Klepper O., Willems W.J., Hosper S.H., Gulati R.D., Van Liere L., Rooijackers R.M.M., Vulnerability to diffuse pollution and average nitrate contamination of European soils and groundwater, Water Sci. Technol. 31 (1995) 159-165.

[25] Moutonnet P., Brandy-Cherrier M., Chambon J., Possibilités d'utilisation des tensiomètres pour l'automation de l'irrigation, Plant and Soil 59 (1981) 335-345.

[26] Moutonnet P., Pagenel J.F., Fardeau J.C., Simultaneous field measurement of nitrate-nitrogen and matric pressure head, Soil Sci. Soc. Am. J. 57 (1993) 1458-1462.

[27] Moutonnet P., Fardeau J.C., Inorganic nitrogen in soil solution collected with Tensionic samplers, Soil Sci. Soc. Am. J. 61 (1997) 822-825.

[28] Poss R., Noble A.D., Dunin F.X., Reyenga W., Evaluation of ceramic cup samplers to measure nitrate leaching in the field, Eur. J. Soil Sci. 46 (1995) 667-674.

[29] Remy J.C., État actuel et perspectives de la mise en œuvre des techniques de prévision de la fumure azotée, C. R. Acad. Agri. Fr. 67 (1981) 859-872.

[30] Shaffer M.J., Halvorson A.D., Pierce F.J., Estimating nitrogen budgets for soil-crop systems, in: Follett R.F., Keeney D.R., Cruse R.M. (Eds.), Managing Nitrogen for Groundwater Quality and Farm Profitability, SSSA, Inc Madison, Wisconsin, USA, 1991, pp. 285-322. 
[31] Sims J.T., Vasilas B.L., Gartley K.L., Milliken B., Green V., Evaluation of soil and plant nitrogen tests for maize on manured soils of the atlantic coastal plain, Agron. J. 87 (1995) 213-222.

[32] Thony J.L., Vachaud G., Vauclin M., Analyse critique de mesures tensiométriques par capteur de pression portatif, Bull. Groupe Français d'Humidité Neutronique 2 (1988) 37-60.
[33] Van Genuchten M.Th., A closed-form equation for predicting the hydraulic conductivity of unsaturated soils, Soil Sci. Soc. Am. J 44 (1980) 892-898.

[34] Vereecken H., Maes J., Feyen J., Estimating unsatured hydraulic conductivity from easily measured soil properties, Soil Sci. 149 (1990) 1-12. 